\title{
The gene yghK linked to the glc operon of Escherichia coli encodes a permease for glycolate that is structurally and functionally similar to L-lactate permease
}

Department of Biochemistry, Faculty of Pharmacy, University of Barcelona, Diagonal 643, 08028 Barcelona, Spain

\author{
M. Felisa Núñez, M. Teresa Pellicer, Josefa Badía, Juan Aguilar \\ and Laura Baldomà
}

Author for correspondence: Juan Aguilar. Tel: +3493403 4496. Fax: + 34944024520. e-mail: jaguilar@farmacia.far.ub.es

\begin{abstract}
In Escherichia coli the glc operon involved in glycolate utilization is located at 67.3 $\mathrm{min}$ and formed by genes encoding the enzymes glycolate oxidase ( $g / c D E F)$ and malate synthase $G$ (glcB). Their expression from a single promoter upstream of glcD is induced by growth on glycolate and regulated by the activator encoded by the divergently transcribed gene glcC. Gene yghK, located $\mathbf{3 5 0}$ bp downstream of glcB, encodes a hydrophobic protein highly similar to the L-lactate permease encoded by IIdP. Expression studies have shown that the $y g h K$ gene (proposed name glcA) is transcribed from the same promoter as the other glc structural genes and thus belongs to the glc operon. Characterization of a glcA:: cat mutant showed that GICA acts as glycolate permease and that glycolate can also enter the cell through another transport system. Evidence is presented of the involvement of L-lactate permease in glycolate uptake. Growth on this compound was abolished in a double mutant of the paralogous genes $\mathrm{glcA}$ and IIdP, and restored with plasmids expressing either GICA or LIdP. Characterization of the putative substrates for these two related permeases showed, in both cases, specificity for the 2-hydroxymonocarboxylates glycolate, L-lactate and D-lactate. Although both GICA and LIdP recognize D-lactate, mutant analysis proved that L-lactate permease is mainly responsible for its uptake.
\end{abstract}

Keywords: gene function assignment, bacterial transport, LctP transporter family, paralogue genes

\section{INTRODUCTION}

Escherichia coli uses glycolate as a carbon and energy source in aerobic conditions. This compound is abundant in nature and especially in algae or plants, where it is an important metabolite of photorespiration (Friedrich et al., 1991; Stewart \& Codd, 1981). Glycolate is metabolized in E. coli through oxidation to glyoxylate (Hansen \& Hayashi, 1962; Kornberg \& Sadler, 1961) in a reaction catalysed by glycolate oxidase (Lord, 1972; Ornston \& Ornston, 1969). Glyoxylate is a branching point in the metabolic pathway since it is metabolized by two divergent reactions. One, catalysed by malate synthase $G$, condenses glyoxylate with acetyl-CoA

Abbreviations: CAA, casein acid hydrolysate; CAT, chloramphenicol acetyltransferase; LB, Luria-Bertani broth; IHF, integration host factor.
(Vanderwinkel \& DeVlieghere, 1968), while the other condenses two molecules of glyoxylate in a process catalysed by glyoxylate carboligase, which simultaneously decarboxylates the intermediate to tartronic semialdehyde (Chang et al., 1993).

The locus $g l c(67 \cdot 3 \mathrm{~min})$, associated with glycolate utilization in Escherichia coli, is known to contain $g l c B$, encoding malate synthase $\mathrm{G}$, the genes $g l c D E F$ needed for glycolate oxidase activity, and $g l c G$, of unknown function (Molina et al., 1994; Pellicer et al., 1996). However, the $g c l$ gene encoding glyoxylate carboligase is not linked to the $g l c$ locus and is located at $12 \mathrm{~min}$ (Chang et al., 1993). The structural genes of the glc locus are organized as an operon $(g l c D E F G B)$ and are transcribed as a single message from a promoter located at the $5^{\prime}$ end of $g l c D$. Expression of this operon is induced by growth on glycolate and is under the control of an 
activator protein encoded by the divergently transcribed gene $g l c C$ (see Fig. 1) Expression is strongly dependent on the integration host factor (IHF) and is repressed by the global respiratory regulator ArcA-P. In vitro gelshift experiments demonstrated direct binding of the promoter DNA to IHF and ArcA-P (Pellicer et al., 1999).

As glycolate $\left(\mathrm{p} K_{\mathrm{a}} 3 \cdot 8\right)$ exists primarily as an anion at physiological $\mathrm{pH}$ it has been postulated that a protein is required for its transport across the cell membrane. Transporters for glycolate have been described in chloroplasts (Howitz \& McCarty, 1991) and in several algae (Wilson \& Tolbert, 1991), but not in bacteria. In eukaryotic cells a monocarboxylate transporter family has been proposed (Halestrap \& Price, 1999) and in mammals, the members of this family are involved in the proton-linked transport of lactate, pyruvate, ketone bodies and acetate in different tissues. Kinetic studies have shown that these transporters can use glycolate as substrate with different affinities (Jackson \& Halestrap, 1996). In bacteria, several lactate permeases have been reported (Matin \& Konings, 1973; Sensen et al., 1996), including a proton-linked activity from E. coli (Collins et al., 1976). However, none of these bacterial permeases displays sequence similarities to the members of the eukaryotic monocarboxylate transporter family.

L-Lactate permease of E. coli is encoded by the $l l d$ operon (formerly labelled $l c t$ ) (Berlyn, 1998). This operon, located at $81.4 \mathrm{~min}$, contains three overlapping genes encoding the permease $(l l d P)$, the regulator protein $(l l d R)$ and the L-lactate dehydrogenase $(l l d D)$. Its transcription is activated by growth on L-lactate from the single promoter upstream of lldP (Dong et al., 1993). No information is available on the substrate specificity of this permease.

In this report we identify the $y g h K$ gene product as a permease for glycolate uptake and characterize it as a transporter structurally and functionally similar to Llactate permease. It is also shown that these two paralogous proteins exhibit a common substrate specificity for 2-hydroxymonocarboxylates.

\section{METHODS}

Bacterial strains, plasmids and phages. All the strains used were E. coli $\mathrm{K}-12$ derivatives. The genotypes and sources of the relevant bacterial strains and plasmids are given in Table 1.

Cell growth. Cells were grown aerobically on Luria-Bertani broth (LB) or minimal medium (Boronat \& Aguilar, 1979). For growth on minimal medium, carbon sources were added at the following concentrations unless otherwise specified: D-xylose, $12 \mathrm{mM}$; D-glucose, $10 \mathrm{mM}$; glycolate and acetate, $30 \mathrm{mM}$; D-lactate, L-lactate and glycerol, $20 \mathrm{mM}$; and casein acid hydrolysate (CAA), $0.5 \%$. The following antibiotic concentrations were used unless otherwise noted: ampicillin, $100 \mu \mathrm{g} \mathrm{ml}^{-1}$; tetracycline, $12.5 \mu \mathrm{g} \mathrm{ml}^{-1}$; kanamycin, $50 \mu \mathrm{g} \mathrm{ml}^{-1}$; and chloramphenicol, $30 \mu \mathrm{g} \mathrm{ml}^{-1}$. X-Gal and IPTG were used at 30 and $10 \mu \mathrm{g} \mathrm{ml}^{-1}$, respectively.

Transport and enzyme assays. For uptake assays, chloramphenicol was added at a final concentration of $40 \mu \mathrm{g} \mathrm{ml}^{-1}$ to cultures at the end of exponential phase. After $15 \mathrm{~min}$, the cells were collected, washed twice and suspended in minimal medium (Boronat \& Aguilar, 1979). Glycolate permease activity was determined at $24{ }^{\circ} \mathrm{C}$ from the rate of $\left[{ }^{14} \mathrm{C}\right]$ glycolate $\left[35 \mathrm{mCi} \mathrm{mmol}^{-1}\left(1295 \mathrm{MBq} \mathrm{mmol}^{-1}\right), \mathrm{ICN}\right]$ uptake by whole cells. The assay was started by adding glycolate at $0.03 \mathrm{mM}$ concentration $\left[25 \mathrm{mCi} \mathrm{mmol}^{-1}\left(925 \mathrm{MBq} \mathrm{mmol}^{-1}\right)\right]$ to a suspension of $10^{9}$ cells $\mathrm{ml}^{-1}$. After $5 \mathrm{~s}(5 \mathrm{~s}$ uptake times reflect initial velocities), samples of $100 \mu \mathrm{l}$ were taken and filtered through a $0.45 \mu \mathrm{m}$-pore-size filter. The filters were washed with $5 \mathrm{ml}$ minimal medium, and processed for counting in a scintillator. L-Lactate permease assays were performed in the same conditions with $\mathrm{L}-\left[{ }^{14} \mathrm{C}\right]$ lactate $\left[80 \mathrm{mCi} \mathrm{mmol}^{-1}\left(2960 \mathrm{MBq} \mathrm{mmol}^{-1}\right), \mathrm{ICN}\right]$. Specific activities

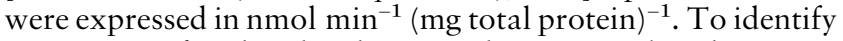
competitors for the glycolate or L-lactate uptake, the assays were performed in the presence of a 20-fold excess of unlabelled carboxylate compounds, unless otherwise specified.

Specific $\beta$-galactosidase activity was assayed at $28{ }^{\circ} \mathrm{C}$ in cells permeabilized with chloroform and SDS, with $o$-nitrophenyl $\beta$-D-galactopyranoside being used as substrate, and expressed as Miller units (Miller, 1992).

Malate synthase (EC 4.1.3.2) and glycolate oxidase (EC 1.1.3.15) activities were assayed in crude extracts prepared as described by Boronat \& Aguilar (1979), in $10 \mathrm{mM}$ Tris/ $\mathrm{HCl}, \mathrm{pH} 8.0$ containing $1 \mathrm{mM} \mathrm{MgCl}$. Total activity of malate synthase, and the relative concentrations of the two isozymes malate synthase $A$ and malate synthase $G$, were determined as described by Ornston \& Ornston (1969). Immunological determination of malate synthase $G$ was carried out by immunoelectrophoresis as described previously (Pellicer et al., 1999). Activity of glycolate oxidase was determined spectrophotometrically according to the method of Lord (1972). As indicated by that author, the $30 \%$ ammonium sulfate fraction resuspended in $10 \mathrm{mM}$ phosphate buffer was routinely used as a source of enzyme to avoid nonspecific reduction of 2,6-dichloroindophenol.

Uptake and activity values reported are the means of at least three separate experiments performed in duplicate. Protein concentration was determined by the Lowry method using bovine serum albumin as standard.

Mutagenesis and genetic techniques. Phage P1 transduction experiments were performed as described by Miller (1992). Tn5 insertion mutagenesis was carried out by infection with phage 2467 (b221 cIts857 rex::Tn5 Oam29 Pam80), as described by Bruijn \& Lupski (1984). Tn5 insertion mutants in the lld operon were obtained from strain MC4100 and selected by their inability to grow on L-lactate.

Primer TN5A (5'-TGGAAAACGGGAAAGGTTCCG-3'), corresponding to an internal sequence of the transposon, was used to amplify and sequence the insertion.

In the gene-inactivation experiments the chloramphenicolresistance gene cassette CAT19 (Fuqua, 1992; Winans et al., 1985) was inserted into the internal HindIII site of the $y g h K$ gene in plasmid pFN11. The plasmid carrying the inactivated gene was linearized by digestion with NruI and used to transform strain JC7623 to chloramphenicol resistance $\left(\mathrm{Cm}^{\mathrm{r}}\right)$. This strain efficiently recombines linear DNA into its chromosome (Winans et al., 1985). P1vir lysates obtained from the selected $\mathrm{Cm}^{\mathrm{r}}$ recombinants were used to transduce the cat insertions into strain MC4100. Chromosomal insertions were confirmed by PCR.

DNA manipulation. Bacterial genomic DNA was obtained as described by Silhavy et al. (1984). Plasmid DNA was routinely 
Table 1. Strains and plasmids used in this work

\begin{tabular}{|c|c|c|}
\hline & Description & Source or reference \\
\hline \multicolumn{3}{|l|}{ E. coli strains } \\
\hline XL-1 Blue & $\begin{array}{l}\text { recA1 lac end A1 gyrA96 thi hsdR17 supE44 relA1 }\left(\mathrm{F}^{\prime}\right. \\
\text { proAB lacl }{ }^{\alpha} \text { lacZ } \Delta \mathrm{M} 15 \text { Tn10) }\end{array}$ & Stratagene \\
\hline MC4100 & araD $\Delta l a c$ rpsL $f l b B$ deoC $p t s F$ rbsR & Casadaban (1976) \\
\hline TE2680 & $\begin{array}{l}\mathrm{F}^{-} \quad \lambda^{-} \mathrm{IN}(r r n D-r r n E) \Delta l a c X 74 \text { rplS galK2 } \\
\quad r e c D:: \operatorname{Tn} 10 d \text {-tet trpDC700::putA13033:: }\left(\operatorname{Kan}^{\mathrm{r}} \mathrm{Cm}^{\mathrm{r}}\right. \\
\text { lac) }\end{array}$ & Elliot (1992) \\
\hline JC7623 & arg thi thr leu pro his strA recB21 recC22 sbcB15 & Wackernagel (1973) \\
\hline CH1827 & $\begin{array}{l}\operatorname{araD139} \Delta(\text { araBC-leu }) 7687 \Delta l a c X 74 \text { galU galK hsdR } \\
\left(\mathrm{r}_{\mathrm{k}}^{-} \mathrm{m}_{\mathrm{k}}^{+}\right) \text {rpsL160 thi zce-726::Tn10 }\end{array}$ & \\
\hline CH1828 & $\mathrm{CH} 1827$ rne-50 & Mudd et al. (1990) \\
\hline JA200 & MC4100 glcA::cat & This work \\
\hline JA201 & MC4100 lldP::Km & This work \\
\hline JA202 & MC4100 glcA::cat lldP::Km & (JA201) P1 × JA200 \\
\hline \multicolumn{3}{|l|}{ Plasmids } \\
\hline pBluescript SK & $\mathrm{Ap}^{\mathrm{r}}$ cloning vector & Stratagene \\
\hline pBR322 & $\mathrm{Ap}^{\mathrm{r}} \mathrm{Tc}^{\mathrm{r}}$ cloning vector & Boehringer Mannheim \\
\hline pCAT19 & $\mathrm{Ap}^{\mathrm{r}} \mathrm{Cm}^{\mathrm{r}}$; source of cat gene & Fuqua $(1992)$ \\
\hline pRS550 & $\mathrm{Ap}^{\mathrm{r}} \mathrm{Km}^{\mathrm{r}} ;$ lac $Z$ fusion vector & Simons et al. (1987) \\
\hline pFN11 & glcABG' (7 kb EcoRI-NruI fragment) in pBR322 & This work \\
\hline pFN12 & glcAB" $4 \cdot 1 \mathrm{~kb}$ SalI-Nsi fragment) in pBR322 & This work \\
\hline pFN20 & lldP in pBR322 & This work \\
\hline
\end{tabular}

prepared by the boiling method (Holmes \& Quigley, 1981). For large-scale preparation, a crude DNA sample was subjected to purification on a column (Qiagen). DNA manipulations were performed essentially as described by Sambrook et al. (1989). DNA sequencing was done by using an automated ABI 377 DNA sequencer and fluorescent dye termination methods. DNA fragments were amplified by PCR using E. coli chromosomal DNA as template. When necessary, specific restriction sites were incorporated at the $5^{\prime}$ end of the primers to facilitate the cloning of the fragments in the appropriate vector. PCR reactions were performed with $p f u$ DNA polymerase in standard conditions.

Plasmid pFN20, bearing the lldP gene, was constructed by cloning into pBR322 a $2.7 \mathrm{~kb}$ PCR fragment containing the entire coding region. The insert of this plasmid was made by using primer LctP1 (5'-GGAGGATCCAGAAGCTGATGAAGATGC-3') and primer LctP2 (5'-GCGAATTCACCAGATACATCCGCTGAC- $3^{\prime}$ ) bearing respectively the $B a m \mathrm{HI}$ and the EcoRI restriction sites (underlined).

Isolation of RNA and Northern blot hybridization. For preparation of total RNA, cells of a $25 \mathrm{ml}$ culture grown to an $\mathrm{OD}_{650}$ of 0.5 were collected by centrifugation at $5000 \mathrm{~g}$ and processed according to Belasco et al. (1985). Northern blot hybridization was performed with each RNA sample $(10 \mu \mathrm{g})$ by the procedure described by Moralejo et al. (1993).

Construction of lacZ fusions to analyse promoter function. Transcriptional fusions were constructed by inserting the DNA fragments into plasmid pRS550 (Simons et al., 1987). This plasmid carries a cryptic lac $Z$ operon and genes that confer resistance to both kanamycin and ampicillin. To construct the glcA-lacZ fusion, the $1382 \mathrm{bp}$ Nsi-BstXI fragment was excised from plasmid pFN11 and ligated into the BamHI site of plasmid pRS550. This fusion comprises
$1145 \mathrm{bp}$ upstream of the translational start site of $g l c A$. To construct a lld-lacZ operon fusion, primers LctP1 (described above) and LctP3 (5'-GCGAATTCAGCGATGCTATCAGACTGG-3') were used to amplify a $0.6 \mathrm{~kb}$ DNA fragment comprising 541 bp upstream of the $l l d P$ translational start site. The fragment was digested with BamHI and EcoRI and cloned into pRS550.

After introduction of the recombinant plasmids into the tetracycline-resistant strain XL-1 Blue, blue colonies were isolated on LB plates containing X-Gal, ampicillin and kanamycin. Plasmid DNA was sequenced by using the M13 primer to ensure that the desired fragment was inserted in the correct orientation. Single-copy fusions on the E. coli chromosome were obtained by the method of Elliot (1992). Plasmids containing the different lac $Z$ fusions were linearized with XhoI and used to transform strain TE2680. Due to the presence in strain TE2680 of the recD:: Tn10 mutation and sequences inserted into the trp operon that are homologous to sequences in pRS plasmids, this strain recombines linear pRS550- or pRS551-based plasmids into its chromosome. The transformants were selected for kanamycin resistance and screened for sensitivity to ampicillin and chloramphenicol. P1vir lysates were made to transduce the fusions into the desired genomic backgrounds.

\section{RESULTS}

\section{Characterization of the $y g h K$ gene}

Sequences flanking the glc locus region made available from the E. coli genome project (Blattner et al., 1997) displayed the entire open reading frame $f 560$ (yghK gene), which was truncated in clone pLB10 described in our previous glc operon study (Pellicer et al., 1996) (Fig. 


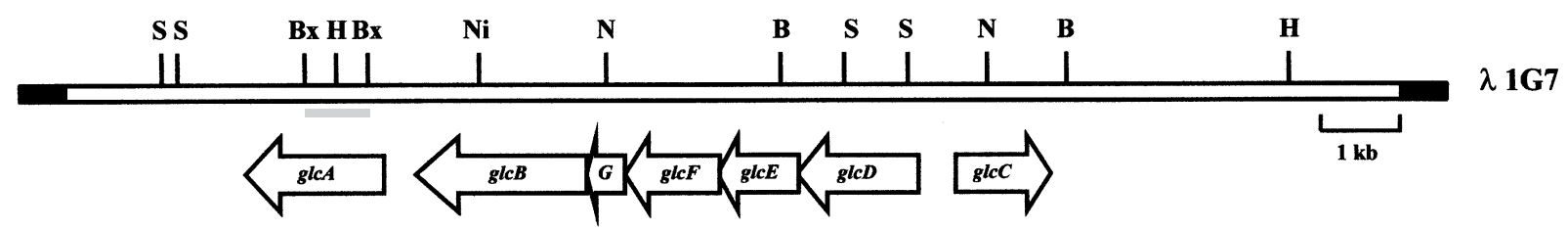

pLB10

pFN11

pFN12

Fig. 1. Restriction map and gene organization of the glc operon. The open bar represents the genomic fragment inserted in clone $\lambda 1 \mathrm{G} 7$ of the Kohara library, and the black bar represents the phage DNA. Relevant restriction sites are shown along the E. coli DNA as follows: B, BamHI; Bx, BstXI; H, HindIII; N, Nrul; Ni, Nsil; S, Sall. Open arrows indicate the direction and position of the glc genes. The inserts of the plasmids used in this study are indicated by thin lines below the map. The grey line over g/cA corresponds to the gene fragment used as probe in the Northern experiments.

1). Here, this gene, located $350 \mathrm{bp}$ downstream of $\mathrm{glcB}$, is referred to as $g l c A$ for its involvement in glycolate utilization. The corresponding amino acid sequence (Q46839) was used as the query sequence for a BLASTP search of the GeneBank database using the NCBI BLAST server. High similarity was found between this sequence and the L-lactate permease encoded by $l l d P$ in E. coli (P33231). Alignment of the GlcA and LldP primary sequences showed an identity of $65 \%$ and a similarity of $80 \%$. According to the protein structure prediction of the NCBI search program, the $g l c A$ gene was shown to encode a highly hydrophobic protein with 13 potential transmembrane segments, suggesting a membrane location for GlcA. It seems likely that this protein corresponds to a membrane permease which could be involved in glycolate transport.

We next cloned the $g l c A$ gene from clone $\lambda 1 \mathrm{G} 7$ of the Kohara library (Kohara et al., 1987). By restriction site analysis and subsequent digestion and ligation a $7 \mathrm{~kb}$ EcoRI-NruI fragment containing $g l c A$ was inserted into pBR322, yielding plasmid pFN11 (Fig. 1). To obtain a recombinant plasmid encoding only glcA but not the neighbouring genes, further subcloning was performed giving rise to plasmid pFN12 (Fig. 1).

\section{Expression of $g / c A$}

Expression of $g l c A$ was studied by Northern blot analysis and by transcriptional fusion experiments of the putative promoter region. For Northern analysis, total RNA was prepared from cultures of wild-type strain MC4100 grown on CAA in the absence or presence of the inducer glycolate. Using a BstXI internal probe of $g l c A$, hybridization bands were only detected with RNA preparations obtained from cultures grown in inducing conditions. In these experiments several bands of $1 \cdot 6-4.0 \mathrm{~kb}$ were observed, possibly due to polycistronic message decay (not shown). To circumvent such a possibility, we grew the RNase E temperaturesensitive mutant strain $\mathrm{CH} 1828$ and its isogenic parent $\mathrm{CH} 1827$ on CAA in the presence of glycolate to compare the results of Northern blots using the same glcA internal

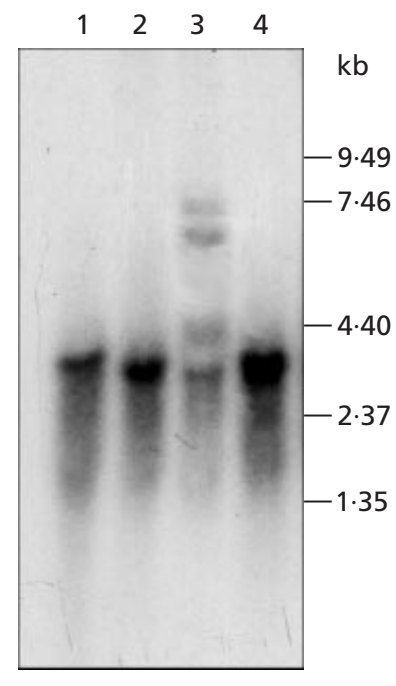

Fig. 2. Northern blot analysis of g/cA expression. Total RNA was obtained from wild-type strain $\mathrm{CH} 1827$ and its isogenic derivative mutant strain $\mathrm{CH} 1828$ with temperature-sensitive RNase $\mathrm{E}$ as follows. Cells were grown at $30^{\circ} \mathrm{C}$ to an $\mathrm{OD}_{650}$ of 0.5 , and a sample of each culture was withdrawn (strain $\mathrm{CH} 1827$, lane 2; strain $\mathrm{CH} 1828$, lane 4) before shifting the growth temperature to $45^{\circ} \mathrm{C}$. A second sample of each culture (strain $\mathrm{CH} 1827$, lane 1; strain $\mathrm{CH} 1828$, lane 3) was taken after 45 min. Hybridization was performed with a $1073 \mathrm{bp}$ glcAspecific probe (BstXI internal fragment).

probe. Only RNA preparations of mutant strain $\mathrm{CH} 1828$ grown at the restrictive temperature showed an mRNA of $8.5 \mathrm{~kb}$ corresponding to the full-length transcript of the glc system (Fig. 2). The same polycistronic mRNA was detected using either $g l c D$ or $g l c B$ as a probe (not shown). Since no internal promoters had been found in the glcDEFGB gene cluster (Pellicer et al., 1999), the presence of multiple bands in these RNA preparations could only be assigned to message decay.

Transcription of the $g l c A$ gene together with genes $g l c D E F G B$ as a single unit was further supported by the absence of promoter activity in the $5^{\prime}$-flanking region of 
Table 2. Growth and glycolate uptake in wild-type and mutant strains

\begin{tabular}{|c|c|c|c|}
\hline Strain & Relevant genotype & $\begin{array}{l}\text { Doubling } \\
\text { time }(h)^{*}\end{array}$ & $\begin{array}{l}{\left[{ }^{14} \mathrm{C}\right] \text { Glycolate uptake }} \\
\left(\mathrm{nmol} \mathrm{min}^{-1} \mathrm{mg}^{-1}\right) \dagger\end{array}$ \\
\hline MC4100 & Wild-type & 5 & $23.1 \pm 1.4$ \\
\hline JA200 & $\operatorname{glc} A:: c a t$ & $8 \cdot 5$ & $7 \cdot 1 \pm 0 \cdot 8$ \\
\hline JA201 & lldP::Tn5 & $6 \cdot 5$ & $10 \cdot 3 \pm 0.7$ \\
\hline JA202 & glcA::cat lldP::Tn5 & - & $<0 \cdot 3$ \\
\hline
\end{tabular}

*Growth rates were measured in minimal medium plus glycolate.

† Due to the inability of strain JA202 to grow on minimal medium plus glycolate, uptake measurements were performed in cells grown on CAA in the presence of $30 \mathrm{mM}$ glycolate.

glcA shown by lacZ fusion experiments. To test any possible promoter function activating this gene expression, a 1382 bp NsiI-BstXI fragment, containing the $350 \mathrm{bp}$ intergenic region upstream of the $g l c A$ start codon, was fused to lacZ. The construction was introduced as a single copy in strain MC4100 and the resulting merodiploid was grown on CAA with or without glycolate as inducer. No $\beta$-galactosidase activity was detected in any of the conditions, indicating the absence of promoter activity in this intergenic fragment.

\section{Role of the glcA gene product in glycolate transport}

Disruption of $g l c A$ by a CAT cassette inserted in the HindIII restriction site and transfer of the mutant gene to the MC4100 genome yielded strain JA200. Growth of this mutant on glycolate was not totally abolished but its rate was much lower than that of the parental strain, with a doubling time of $8.5 \mathrm{~h}$ for strain JA200 and $5 \mathrm{~h}$ for wild-type strain MC4100 (Table 2). Control cultures in CAA, acetate, L-lactate, glucose or glycerol did not display significant differences between JA200 and MC4100.

Levels of glycolate oxidase activity and immunologically detected malate synthase $G$ protein were similar in strains JA200 and MC4100 when grown in the presence of glycolate (not shown). These results indicated that expression of the structural genes of the glc system was not affected by the cat insertion. Consistently, expression of a transcriptional fusion of the glc operon, $\Phi(g l c D-l a c Z)$ (Pellicer et al., 1999), in the genetic background of strain JA200 yielded the same $\beta$-galactosidase activity as strain MC4100 (not shown). Thus, the slow growth of strain JA200 on glycolate was not due to a reduced metabolic rate and may be explained by lower transport activity. The rate of entry of radioactive glycolate was measured in mutant strain JA200 and its parental strain grown in the presence of glycolate. The rate of glycolate uptake in the $g l c A$ mutant was not null but diminished to one-third of the value determined in wild-type cells (Table 2).

Specific dependence of radioactive glycolate uptake on the transporter function was ascertained by performing the experiments in cells where the metabolic carbon incorporation was made negligible. Glycolate oxidase mutants, deficient in metabolism of the substrate, could

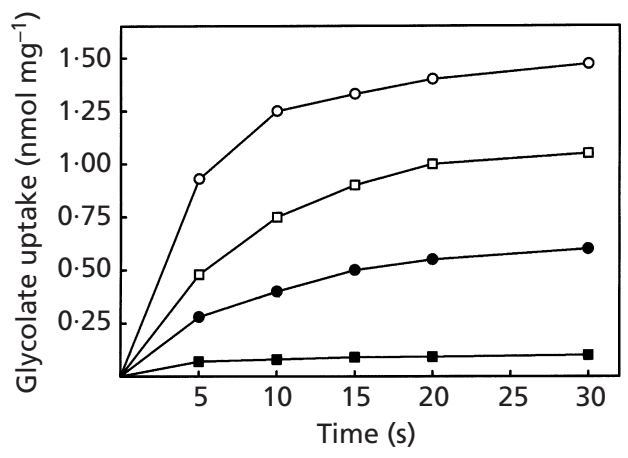

Fig. 3. Dependence of glycolate transport on the presence of the functional GlcA or LldP proteins. Time course of $\left[{ }^{14} \mathrm{C}\right]$ glycolate uptake by whole cells grown in the presence of glycolate was performed at $10{ }^{\circ} \mathrm{C}$ for strains MC4100 (O), JA200 (৩), JA201 ( $\square$ ) and JA202 (ם).

not be used for this purpose because they yielded artifactual results due to the accumulation of endogenous glycolate and overexpression of the glc sytsem. Instead we minimized the metabolic contribution to radioactive incorporation by carrying out the transport experiments at $10{ }^{\circ} \mathrm{C}$. In these conditions the time course of uptake is asymptotic and proportional to the transporter function, with an initial rate for mutant JA200 about one-third of that found for wild-type cells (Fig. 3).

These results support the hypothesis that $g l c A$ encodes a glycolate permease and suggest that glycolate also enters the cell through another transport protein. Consistent with the role of $g l c A$ in the transport of glycolate is the fact that the growth rate on this carbon source was restored when the $g l c A:: c a t$ mutant strain JA200 was transformed with plasmid pFN12.

\section{Glycolate transport through L-lactate permease}

The high similarity between the L-lactate and glycolate permeases indicated above, which led some authors to classify them in the same family (Saier, 2000), opens the possibility that the L-lactate permease could be the alternative transport system for glycolate. This hypothesis was explored in experiments in which glycolate was used as competitor for L-lactate uptake in cells of strain JA200 induced by growth on L-lactate. Activities 
Table 3. Competition of different carboxylates with the uptake of glycolate through GIcA or with the uptake of L-lactate through LIdP

\begin{tabular}{|c|c|c|c|c|}
\hline \multirow[t]{2}{*}{$\begin{array}{l}\text { Competing } \\
\text { carboxylate }\end{array}$} & \multicolumn{2}{|c|}{$\begin{array}{c}{\left[{ }^{14} \mathrm{C}\right] \text { Glycolate uptake }} \\
\text { in strain JA201* }\end{array}$} & \multicolumn{2}{|c|}{$\begin{array}{l}\mathrm{L}-\left[{ }^{14} \mathrm{C}\right] \text { Lactate uptake } \\
\text { in strain JA200* }\end{array}$} \\
\hline & Rate $†$ & $\begin{array}{l}\% \text { of JA201 } \\
\text { control }\end{array}$ & Rate $†$ & $\begin{array}{c}\% \text { of JA200 } \\
\text { control }\end{array}$ \\
\hline None & $10 \cdot 1 \pm 0 \cdot 8$ & 100 & $3 \cdot 6 \pm 0 \cdot 4$ & 100 \\
\hline Glycolate & - & - & $2 \cdot 2 \pm 0 \cdot 3$ & 60 \\
\hline L-Lactate & $1 \cdot 8 \pm 0.3$ & 18 & - & - \\
\hline D-Lactate & $2 \cdot 4 \pm 0.4$ & 24 & $1 \cdot 5 \pm 0 \cdot 3$ & 43 \\
\hline L-Glycerate & $7 \cdot 1 \pm 0.8$ & 70 & $3 \cdot 4 \pm 0 \cdot 3$ & 95 \\
\hline D-Glycerate & $7 \cdot 3 \pm 0.7$ & 72 & $3 \cdot 6 \pm 0 \cdot 2$ & 99 \\
\hline Acetate & $10 \cdot 6 \pm 0 \cdot 9$ & 105 & $3.8 \pm 0.4$ & 105 \\
\hline Malate & $11 \cdot 1 \pm 1 \cdot 0$ & 110 & $3.8 \pm 0.4$ & 105 \\
\hline Succinate & $9 \cdot 9 \pm 0 \cdot 8$ & 99 & $3 \cdot 5 \pm 0 \cdot 3$ & 97 \\
\hline Citrate & $10 \cdot 3 \pm 0 \cdot 7$ & 102 & $3 \cdot 6 \pm 0 \cdot 4$ & 99 \\
\hline
\end{tabular}

* Uptake was measured using $0.03 \mathrm{mM}\left[{ }^{14} \mathrm{C}\right]$ glycolate or L- $\left[{ }^{14} \mathrm{C}\right]$ lactate in the presence of $0.6 \mathrm{mM}$ competing carboxylate.

† Rate is expressed as nmol $\mathrm{min}^{-1}$ (mg total protein $)^{-1}$.

of L-lactate permease were indeed inhibited by increasing concentrations of glycolate in the assay mixture. When added at a concentration 10-fold higher than that of the labelled substrate, glycolate caused a $25 \%$ inhibition with respect to the rate of L-lactate uptake in the absence of any competitor.

Further evidence of the involvement of L-lactate permease in glycolate uptake was obtained with a $\operatorname{Tn} 5$ insertion mutant in $l l d P$ obtained as described in Methods. To rule out the possibility of multiple transposon insertions, this mutation was P1-transduced into the wild-type strain MC4100 and again selected for the same phenotype (strain JA201). Location of the Tn5 insertion in $l l d P$ was first mapped by PCR amplification of JA201 chromosomal DNA using the specific transposon primer TN5A and oligonucleotides LctP1 and LctP2 flanking the $l l d P$ gene. The precise location was determined by sequencing the region adjacent to the Tn 5 joining site using primer TN5A. Analysis of this sequence showed that the $\operatorname{Tn} 5$ transposon was inserted 341 nucleotides downstream of the start codon of gene IldP. A double mutant defective in both L-lactate permease and glycolate permease was constructed by introducing the $l l d P:: \operatorname{Tn} 5$ mutation into the genomic background of strain JA200, yielding strain JA202.

Strain JA201 displayed a glycolate uptake around 50\% lower than the wild-type cells. Consistently, the growth rate of strain JA201 on glycolate was slightly lower than wild-type, with a doubling time of $6.5 \mathrm{~h}$. The double mutant strain JA202 was unable to grow on glycolate and displayed undetectable glycolate uptake when grown on CAA in the presence of glycolate (Table 2). This double mutant recovered the ability to grow on glycolate when transformed with plasmids pFN12 or pFN20, expressing GlcA or LldP respectively.
Time-course experiments performed at $10{ }^{\circ} \mathrm{C}$ showed for mutant JA201 an initial rate one-half of that found for the wild-type cells and a null incorporation for the double mutant JA202, thus proving again the specific dependence of the measured transport on the activity of the proposed transporters (Fig. 3). To show that the mutant strain JA202 had no other metabolic functions altered, we tested the growth rates on other carbon sources such as L-rhamnose, glycerol, D-xylose or acetate, and also determined the proton-linked Lrhamnose uptake (not shown). No differences were observed with respect to the wild-type strain.

\section{Substrate specificity of GIcA and LldP transport proteins}

The common recognition of glycolate by both permeases led us to study their specificity for other substrates. This was approached by using a set of different mono-, diand tricarboxylate compounds as competitors of the physiological substrate uptake.

Putative substrates for GlcA were tested in cells of strain JA201, defective in L-lactate permease. These mutant cells were grown on glycolate and uptake of labelled glycolate was measured in the presence of a 20 -fold excess of each of the competitors. None of the dicarboxylates (succinate, malate) or the tricarboxylate (citrate) tested inhibited glycolate uptake. Among the monocarboxylates, only 2-hydroxymonocarboxylates were good competitors and among them $\mathrm{D}$ - and L-lactate were the most effective (75 and $80 \%$ inhibition respectively) (Table 3). No significant changes in the uptake rate were observed in the presence of acetate.

The putative substrates for the L-lactate permease were defined in a parallel competition experiment with cells 
Table 4. Expression of g/c and /ld operon fusions

\begin{tabular}{|lcc|}
\hline Carbon source & \multicolumn{2}{c|}{$\boldsymbol{\beta}$-Galactosidase activity } \\
& \multicolumn{2}{c|}{ (Miller units) } \\
\cline { 2 - 3 } & $\begin{array}{c}\text { MC4100 } \\
\boldsymbol{\Phi}(\boldsymbol{g l} \boldsymbol{c} \boldsymbol{D}-\mathbf{l a c} \boldsymbol{Z})\end{array}$ & $\begin{array}{c}\text { MC4100 } \\
\boldsymbol{\Phi}(\text { lld } \boldsymbol{P}-\text { lac } \boldsymbol{Z})\end{array}$ \\
\hline CAA & $125 \pm 10$ & $220 \pm 9$ \\
D-Xylose & $97 \pm 7$ & $205 \pm 5$ \\
Glycolate & $3158 \pm 83$ & $270 \pm 9$ \\
L-Lactate & $94 \pm 8$ & $2020 \pm 91$ \\
D-Lactate & $639 \pm 34$ & $1053 \pm 42$ \\
\hline
\end{tabular}

of GlcA-deficient mutant strain JA200 grown on Llactate. The pattern of competition with L-lactate uptake was similar to that described above for glycolate uptake except for L- and D-glycerate, which caused uptake inhibition only for glycolate permease (Table 3 ). Nevertheless, when tested at higher concentrations (100-fold) these compounds also inhibited L-lactate uptake. Thus, both GlcA and LldP transporters share the specificity for 2-hydroxymonocarboxylates.

\section{Identification of the permease for D-lactate}

As D-lactate competed with the uptake mediated by GlcA and LldP, identification of the transport system accounting for the D-lactate uptake was undertaken by testing the growth of mutant strains JA200, JA201 and JA202 on this carbon source. The glcA mutation (strain JA200) did not reduce the growth rate on D-lactate, while the $l l d P:: \operatorname{Tn} 5$ mutation (strain JA201) impaired growth on this carbon source, indicating that the transport of this compound was mainly carried out by the $l l d P$ product.

Growth of double mutant strain JA202 on D-lactate was restored by plasmids expressing GlcA (pFN12) or LldP ( $p F N 20)$, indicating that both permeases transport this 2-hydroxycarboxylate compound as substrate when appropriately overexpressed.

\section{Cross-induction of g/c and IId operons by related 2-hydroxymonocarboxylates}

Since genetic experiments have shown that L-lactate permease is involved in the transport of D-lactate and glycolate across the cell membrane, we analysed the ability of these compounds to induce the expression of the lld operon. Induction of the glc operon by growth in the presence of both lactate isomers was also analysed. To this end, cells of wild-type-strain MC4100 bearing $\Phi(g l c D-l a c Z)$ or $\Phi(l l d P-l a c Z)$ were grown on glycolate, D-lactate, L-lactate, CAA or $\mathrm{D}$-xylose. Levels of $\beta$ galactosidase activity indicated that glycolate and Llactate were highly specific, inducing only their own operons (Table 4). D-Lactate displayed a weak induction of the $g l c$ operon and a significant induction of the $l l d$ operon to a level approximately one-half of that observed with L-lactate (Table 4).

\section{DISCUSSION}

The E. coli genes $y g h K$ of unknown function and $l l d P$ encoding L-lactate permease have been classified as paralogues by computational analysis. On the basis of this similarity the SWISS-PROT database tentatively assigned to $y g h K$ gene product a function of L-lactate permease. In this work we present evidence that the $y g h K$ gene $(g l c A)$ is closely linked to the $g l c$ genetic system and its gene product has a role in the transport of glycolate. The $350 \mathrm{bp}$ intergenic region between $\mathrm{glcA}$ and the end of the previously described $g l c$ operon suggests the presence of a specific promoter for the expression of this gene. However, transcriptional fusion experiments failed to identify any promoter activity in the intergenic region, while Northern blot analysis revealed a band corresponding to the full-length polycistronic message, thus including $g l c A$ in the glc operon. This is in accordance with the participation of GlcA in the metabolism of glycolate, a finding further supported by the fact that the disruption of this gene significantly affected glycolate dissimilation.

Sequence analysis suggested that GlcA is a membrane protein. The high similarity with L-lactate permease further indicated its role in the transport of substrates structurally related to hydroxycarboxylates. Results presented in this study indeed confirmed that GlcA was involved in glycolate transport when the cells were induced by growth on this carbon source. Nevertheless, the ability of strain JA200 ( $g l c A:: c a t)$ to utilize glycolate indicated that glycolate enters the cell through another transport system, most likely the system encoded by the paralogous gene $l l d P$. Our experiments of $l l d P$ disruption and characterization of the double mutant glcA::cat lldP::Tn5 showed that glycolate enters the cell simultaneously via the two permeases. Although glycolate did not induce $l l d$, the basal expression of this operon appears to be sufficient for uptake of glycolate at rates which can support growth.

The results obtained in the competition experiments with other candidate substrates show that both glycolate and L-lactate permeases display specificity for L-lactate, D-lactate and glycolate. Consistently, clones expressing GlcA or LldP restored growth of strain JA202 on glycolate or on D-lactate. The ability of these plasmids to restore growth on L-lactate could not be analysed due to polar effects of the Tn5 insertion in $l l d P$ on expression of the downstream gene encoding L-lactate dehydrogenase. Nevertheless, physiological uptake of both lactate isomers is carried out mainly by LldP, since disruption of $g l c A$ did not reduce the growth rate on these carbon sources. Former studies (Matin \& Konings, 1973) suggested that D- and L-lactate share a permease other than the dicarboxylate transport system, although no precise assignment to a specific protein was proposed at that time for D-lactate. For these reasons, our findings of D-lactate recognition by L-lactate permease and the induction of the lld operon by this isomer could be of physiological importance in providing an efficient transport system for this compound. 
Finally, on the basis of sequence similarity, it is worth mentioning that $g l c A$ - and $l l d P$-encoded proteins have been included in the LctP family of secondary transporters (http://www.biology.ucsd.edu/ ipaulsen/ transport). Here we have shown that these two transporters specifically recognize 2-hydroxymonocarboxylates. However, unlike the 2-hydroxycarboxylate transporters of lactic acid bacteria (Bandell et al., 1997), they do not transport malate and, in contrast to the monocarboxylate transporter family, they do not recognize acetate (Halestrap \& Price, 1999).

\section{ACKNOWLEDGEMENTS}

This work was supported by grant PB97-0920 from the Dirección General de Enseñanza Superior e Investigación Cientifica, Madrid, Spain, and partially by the help of the 'Comissionat per Universitats i Recerca de la Generalitat de Catalunya'. F.N. is the recipient of a predoctoral fellowship from the Generalitat de Catalunya.

\section{REFERENCES}

Bandell, M., Ansanay, V., Rachidi, N., Dequin, S. \& Lolkema, J. S. (1997). Membrane potential-generating malate (MleP) and citrate (CitP) transporters of lactic acid bacteria are homologous proteins. Substrate specificity of the 2-hydroxycarboxylate transporter family. J Biol Chem 272, 18140-18146.

Belasco, J. G., Beatty, T., Adams, C. W., von Gabain, A. \& Cohen, S. N. (1985). Differential expression of photosynthesis genes in $R$. capsulata results from segmental differences in stability within the polycistronic $r x c A$ transcript. Cell 40, 171-181.

Berlyn, M. K. B. (1998). Linkage map of Escherichia coli K12, edition 10: the traditional map. Microbiol Mol Biol Rev 62, 814-984.

Blattner, F. R., Plunkett, G., III, Bloch, C. A. \& 14 other authors (1997). The complete genome sequence of the Escherichia coli K-12. Science 277, 1453-1462.

Boronat, A. \& Aguilar, J. (1979). Rhamnose-induced propanediol oxidoreductase in Escherichia coli: purification, properties, and comparison with the fucose-induced enzyme. J Bacteriol 140, 320-326.

Bruijn, F. J. \& Lupski, J. R. (1984). The use of transposon Tn5 mutagenesis in the rapid generation of correlated physical and genetic maps of DNA segments cloned into multicopy plasmids. Gene 27, 131-149.

Casadaban, M. J. (1976). Transposition and fusion of the lac genes to selected promoters in Escherichia coli using bacteriophage lambda and Mu. J Mol Biol 104, 541-555.

Chang, Y. Y., Wang, A. Y. \& Cronan, J. E., Jr (1993). Molecular cloning, DNA sequencing, and biochemical analysis of Escherichia coli glyoxylate carboligase. J Biol Chem 268, 3911-3919.

Collins, S. H., Jarvis, A. W., Lindsay, R. J. \& Hamilton, W. A. (1976). Proton movements coupled to lactate and alanine transport in Escherichia coli: isolation of mutants with altered stoichiometry in alanine transport. J Bacteriol 126, 1232-1244.

Dong, J. M., Taylor, J. S., Latour, D. J., Iuchi, S. \& Lin, E. C. C. (1993). Three overlapping $l c t$ genes involved in L-lactate utilization by Escherichia coli. J Bacteriol 175, 6671-6678.
Elliot, T. (1992). A method for constructing single copy lac fusions in Salmonella typhimurium and its application to the hemA-prfA operon. J Bacteriol 174, 245-253.

Friedrich, M., Laderer, U. \& Schink, B. (1991). Fermentative degradation of glycolic acid by defined syntrophic cocultures. Arch Microbiol 156, 398-404.

Fuqua, W. C. (1992). An improved chloramphenicol resistance gene cassette for site-directed marker replacement mutagenesis. Biotechniques 12, 223-225.

Halestrap, A. P. \& Price, N. T. (1999). The proton-linked monocarboxylate transporter (MCT) family: structure, function and regulation. Biochem J 343, 281-299.

Hansen, R. W. \& Hayashi, J. A. (1962). Glycollate metabolism in Escherichia coli. J Bacteriol 83, 679-687.

Holmes, D. S. \& Quigley, M. (1981). A rapid boiling method for the preparation of bacterial plasmids. Anal Biochem 114, 193-197.

Howitz, K. T. \& McCarty, R. E. (1991). Solubilization, partial purification, and reconstitution of the glycolate/glycerate transporter from chloroplast inner envelope membranes. Plant Physiol 96, 1060-1069.

Jackson, V. N. \& Halestrap, A. P. (1996). The kinetics, substrate, and inhibitor specificity of the monocarboxylate (lactate) transporter of rat liver cells determined using the fluorescent intracellular $\mathrm{pH}$ indicator, 2',7'-bis(carboxyethyl)-5(6)-carboxyfluorescein. J Biol Chem 271, 861-868.

Kohara, Y., Akiyame, K. \& Isono, K. (1987). The physical map of the whole Escherichia coli chromosome. Application of a new strategy for rapid analysis and sorting of a large genomic library. Cell 50, 495-501.

Kornberg, H. L. \& Sadler, J. R. (1961). The metabolism of $\mathrm{C}_{2}$ compounds in microorganisms. 8. A dicarboxylic acid cycle as a route for the oxidation of glycollate by Escherichia coli. Biochem J 81, 503-513.

Lord, J. M. (1972). Glycolate oxidoreductase in Escherichia coli. Biochim Biophys Acta 267, 227-237.

Matin, A. \& Konings, W. N. (1973). Transport of lactate and succinate by membrane vesicles of Escherichia coli, Bacillus subtilis and a Pseudomonas species. Eur J Biochem 34, 58-67.

Miller, J. H. (1992). A Short Course in Bacterial Genetics. Cold Spring Harbor, NY: Cold Spring Harbor Laboratory.

Molina, I., Pellicer, M.-T., Badia, J., Aguilar, J. \& Baldomà, L. (1994). Molecular characterization of Escherichia coli malate synthase G. Differentiation with the malate synthase A isoenzyme. Eur J Biochem 224, 541-548.

Moralejo, P., Egan, S. M., Hidalgo, E. \& Aguilar, J. (1993). Sequencing and characterization of a gene cluster encoding the enzymes for L-rhamnose metabolism in Escherichia coli. J Bacteriol 175, 5585-5594.

Mudd, E. A., Krisch, H. M. \& Higgins, C. F. (1990). RNAseE, an endoribonuclease, has a general role in the chemical decay of Escherichia coli mRNA: evidence that rne and ams are the same genetic locus. Mol Microbiol 4, 2127-2135.

Ornston, L. N. \& Ornston, M. K. (1969). Regulation of glyoxylate metabolism in Escherichia coli K12. J Bacteriol 98, 1098-1108.

Pellicer, M.-T., Badia, J., Aguilar, J. \& Baldomà, L. (1996). glc locus of Escherichia coli: characterization of genes encoding the subunits of glycolate oxidase and the $g l c$ regulator protein. $J$ Bacteriol 178, 2051-2059.

Pellicer, M.-T., Fernandez, C., Badia, J., Aguilar, J., Lin, E. C. C. \& Baldomà, L. (1999). Cross-induction of glc and ace operons of 
Escherichia coli attributable to pathway intersection. Characterization of the glc promoter. J Biol Chem 274, 1745-1752.

Sambrook, J., Fritsch, E. F. \& Maniatis, T. (1989). Molecular Cloning: a Laboratory Manual, 2nd edn. Cold Spring Harbor, NY: Cold Spring Harbor Laboratory.

Sensen, C. W., Klenk, H. P., Singh, R. K. \& 10 other authors (1996). Organizational characteristics and information content of an archaeal genome: $156 \mathrm{~kb}$ of sequence from Sulfolobus sofataricus P2. Mol Microbiol 22, 175-191.

Saier, M. H., Jr (2000). Families of transmembrane sugar transport proteins. Mol Microbiol 35, 699-710.

Silhavy, T. J., Berman, M. L. \& Enquist, L. (1984). Experiments with Gene Fusions. Cold Spring Harbor, NY: Cold Spring Harbor Laboratory.

Simons, R. W., Houman, F. \& Kleckner, N. (1987). Improved single and multicopy lac-based cloning vectors for protein and operon fusions. Gene 53, 85-96.
Stewart, R. \& Codd, G. A. (1981). Glycollate and glyoxylate excretion by Sphaerocystis schroeteri (Chlorophylaceae). $\mathrm{Br}$ Phycol J 16, 177-182.

Vanderwinkel, E. \& De Vlieghere, M. (1968). Physiologie et génétique de l'isocitritase et des malate synthases chez Escherichia coli. Eur J Biochem 5, 81-90.

Wackernagel, W. (1973). Genetic transformation in E. coli: the inhibitory role of the recBC DNAse. Biochem Biophys Res Commun 51, 306-311.

Wilson, B. J. \& Tolbert, N. E. (1991). The transport of glycolic acid by Chlamydomonas reinhardtii. FEBS Lett 279, 313-315.

Winans, S. C., Elledge, S. J., Krueger, J. H. \& Walker, G. C. (1985). Site-directed insertion and deletion mutagenesis with cloned fragments in Escherichia coli. J Bacteriol 161, 1219-1221.

Received 22 September 2000; revised 11 December 2000; accepted 18 December 2000. 